\title{
Efficiency and Effectiveness Method versus $\varepsilon$-NTU Method with Application in Finned Flat Tube Compact Heat Exchanger with Water-Ethylene Glycol as Nanofluid Base of Iron Oxide Nanoparticles
}

\author{
Élcio Nogueira \\ Department of Mechanic and Energy, State University of Rio de Janeiro, Rio de Janeiro, Brazil \\ Email: elcionogueira@hotmail.com
}

How to cite this paper: Nogueira, É. (2022) Efficiency and Effectiveness Method versus $\varepsilon$-NTU Method with Application in Finned Flat Tube Compact Heat Exchanger with Water-Ethylene Glycol as Nanofluid Base of Iron Oxide Nanoparticles. Journal of Materials Science and Chemical Engineering, 10, 1-17.

https://doi.org/10.4236/msce.2022.102001

Received: December 10, 2021

Accepted: February 15, 2022

Published: February 18, 2022

Copyright $\odot 2022$ by author(s) and Scientific Research Publishing Inc. This work is licensed under the Creative Commons Attribution International License (CC BY 4.0).

http://creativecommons.org/licenses/by/4.0/

\begin{abstract}
This work aims to establish comparisons between two models used for the performance of heat exchangers. The chosen system, in this case, consists of a heat exchanger used in automotive radiators flat finned tube type. Water and ethylene glycol compound as base fluid and volume fractions of iron oxide nanoparticles $\left(\mathrm{Fe}_{3} \mathrm{O}_{4}\right)$ are used as a refrigerant. The quantities determined in this work are the nanofluid exit temperature, the air exit temperature, the absolute error between the models for heat transfer rate, and Effectiveness. The quantities that constitute parameters, independent variables, are the airflow, represented by the Reynolds number, and the iron oxide volume fraction. Ethylene Glycol 50\% compound has slightly better thermal performance than pure water and reduces the reactive effect of water on the environment, increasing the average life of the equipment. The absolute relative error between the models is less than $20 \%$ and presents maximum values with the increase of the nanoparticle volume fraction and growth in the Reynolds number for the air.
\end{abstract}

\section{Keywords}

Efficiency and Effectiveness Method, $\varepsilon$-NTU Method, Compact Heat Exchanger, Iron Oxid Nanoparticles, Nanofluid

\section{Introduction}

This K.Y. Leong et al. [1] analyze the energy performance of three different heli- 
cal heat exchangers using ethylene glycol and copper nanoparticles. The main parameters used in the comparison were the heat transfer rate and the entropy generation rate. The analyzed heat exchangers are of the segmental baffle type, $25^{\circ}$ and $50^{\circ}$. The study indicates that heat exchangers with $50^{\circ}$ helical baffles exhibit lower entropy generation. In addition, they report that with only $0.3 \%$ of the volume fraction of copper nanoparticles in the base fluid, there is an increase in thermal conductivity of $40 \%$. The nanoparticles' volume fraction, thermal conductivity, and viscosities affect heat transfer and entropy generation.

Tiwari R, Maheshwari G. [2] argues that several methods have been applied to optimize the thermodynamic performance of heat exchangers and that the concept of Effectiveness generally is used to measure this. However, Effectiveness only does not provide information about Efficiency and Irreversibility. These concepts were necessary for determining entropy generation based on the second law of thermodynamics. It argues that to have the best performance, in terms of Effectiveness and Efficiency, the heat exchanger must operate with low values for the relationship between the fluids' thermal capacities. For example, a ratio equal to 0.5 enables optimal performance for heat exchangers of the type of counterflow.

Ahmad Fakheri [3] defines thermal efficiency for heat exchangers based on the second law of thermodynamics. It shows an ideal heat exchanger, corresponding to a balanced counterflow heat exchanger, and that thermal capacity ratings are equal to the minimum thermal capacity rating of the real heat exchanger. The ideal heat exchanger is more efficient and less irreversible because it generates the least entropy. The concept of efficiency is a precise measure of a system's performance and shows how close it is to the ideal and whether possible improvements are feasible and justified. The most used approaches for analyzing heat exchangers are LMTD and $\varepsilon$-NTU. The LMTD approach is generally used for solving sizing problems. The $\mathcal{\varepsilon}$-NTU method is mainly used for the rating problem, although sizing problems can also be solved with this method. However, the concept of heat exchanger efficiency based on the second law also provides the solution to both problems and a new way to design and analyze heat exchangers and networks.

Selvam C. et al. [4] use graphene nanoplate-based nanofluid as the coolant and report an increase in an automobile radiator's overall heat transfer coefficient. Water-ethylene glycol was used as the base fluid. The general heat transfer coefficient increases with the rise in the nanofluid inlet temperature and volume fraction of the graphene nanoplates. They demonstrate that the nanofluid mass flow has a more significant influence on the pressure drop than the volume fraction of graphene nanoplates. They argue that graphene-based nanofluids can substitute conventional fluids in an automobile radiator to improve thermal performance.

Nogueira E. [5] uses a mixture of water-ethylene glycol (50\%) flowing in the shell and nanofluid flowing in the tube $\left(\mathrm{Ag}\right.$ or $\left.\mathrm{Al}_{2} \mathrm{O}_{3}\right)$ to obtain the heat exchanger exit temperatures. It applies the concepts of Efficiency, Effectiveness, 
and thermal irreversibility to get and discuss results. He demonstrates that a higher value for thermal conductivity allows greater thermal efficiency. High efficiency, associated with increased thermal irreversibility, leads to lower tube temperatures for the laminar regime. The conductive effect is more relevant in thermal diffusivity in the laminar regime, where the high-volume fractions of nanoparticles have a more considerable influence on the exit temperatures.

Hussein A.M. et al. [6] present an experimental and numerical study to improve heat transfer and minimize the pressure drop in an automotive refrigeration system. $\mathrm{TiO}_{2}$ and $\mathrm{SiO}_{2}$ nanoparticles were added in four different base fluids, and the thermophysical properties were measured and validated. The simulation results are in good agreement with the experimental data. $\mathrm{SiO}_{2}$ has higher values for friction factor and heat transfer coefficient than $\mathrm{TiO}_{2}$. The work defined input parameters that significantly improve heat transfer in the automotive cooling system, and the theoretical-experimental comparison shows a maximum deviation of $10 \%$.

Élcio Nogueira [7] applies the effectiveness method ( $\varepsilon$-NTU) to analyze the thermal performance of a multi-louvered flat tube radiator using a suspension of silver nanoparticles in ethylene glycol. Determines the heat transfer rate, efficiency, and exit temperatures of nanofluid and air. The analysis presents promising results, as it demonstrates that it is possible to reduce the internal storage space of the refrigerant. Furthermore, it indicates that the best heat exchanger performance occurs for a relatively low fraction of silver nanoparticles for the turbulent regime when the nanofluid's thermal diffusivity becomes more effective. Finally, he points out that the methodology does not apply to high fractions of nanoparticles, as the flow is no longer Newtonian.

Élcio Nogueira [8] uses Graphene Nanoribbon and Silicon Carbide to analyze a flat tube multi-louvered fin radiator's thermal and hydraulic performance on a fluid composed of pure water and ethylene glycol in a volume fraction equal to $50 \%$. The Nusselt number, convection heat transfer coefficient, and pressure drop are graphically presented. Reynolds number, nanofluid mass flow rate, Colburn factor, and friction factor are the main parameters used to determine the results. In some situations, the volume fraction of nanoparticles underwent variations. The flow rate is laminar, whatever the value of the fraction by volume of the nanoparticles when the mass flow rate of the nanofluid is relatively low. The heat transfer coefficient is significantly high for Graphene Nanoribbon for a turbulent flow regime and a relatively small fraction of nanoparticles. Since lower values for the volume fraction, the favorable result can reduce heat exchanger costs.

Table 1 below shows the properties of water, 50\% ethylene glycol, and iron oxide.

Figure 1 schematically represents a finned flat tube heat exchanger used in automotive radiators.

The formulations for both models are found below. 


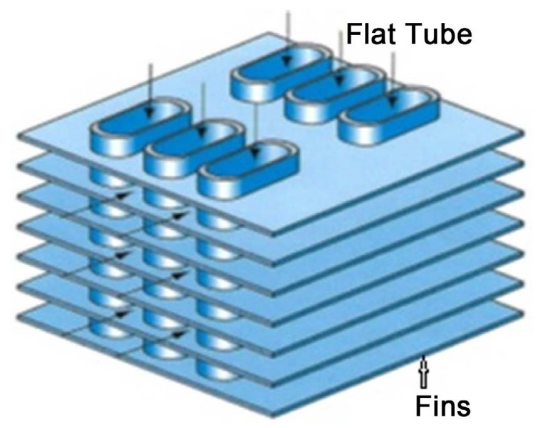

Figure 1. Flat finned tube compact heat exchanger.

Table 1. Properties of pure water, ethylene glycol 50\%, and iron oxide.

\begin{tabular}{cccccc}
\hline & $\begin{array}{c}\rho \\
\mathrm{kg} / \mathrm{m}^{3}\end{array}$ & $\begin{array}{c}k \\
\mathrm{~W} /(\mathrm{m} \mathrm{K})\end{array}$ & $\begin{array}{c}C p \\
\mathrm{~J} /(\mathrm{kg} \mathrm{K})\end{array}$ & $\begin{array}{c}\alpha \\
\mathrm{m}^{2} / \mathrm{s}\end{array}$ & $\begin{array}{c}\mu \\
\mathrm{kg} /(\mathrm{m} \mathrm{s})\end{array}$ \\
\hline Pure Water & 999 & 0.607 & 4186 & $1.45 \times 10^{-6}$ & $1.002 \times 10^{-3}$ \\
Ethylene Glycol 50\% & 1058 & 0.422 & 3879 & $0.6 \times 10^{-6}$ & $9.81 \times 10^{-4}$ \\
$\mathrm{Fe}_{3} \mathrm{O}_{4}$ & 5200 & 6.0 & 670 & 1.29353 & - \\
\hline
\end{tabular}

\section{Methodology}

This work aims to establish comparisons between two models used for the performance of heat exchangers. The chosen system, in this case, consists of a heat exchanger used in automotive radiators flat finned tube type. A water and ethylene glycol compound as base fluid and volume fractions of iron oxide nanoparticles $\left(\mathrm{Fe}_{3} \mathrm{O}_{4}\right)$ are used as a refrigerant. The quantities determined in this work are the nanofluid exit temperature, the air exit temperature, the absolute error between the models for heat transfer rate, and Effectiveness. The quantities that constitute parameters, independent variables, are the airflow, represented by the Reynolds number, and the iron oxide volume fraction.

\subsection{Efficiency and Effectiveness Method}

$$
\begin{aligned}
\operatorname{Tin}_{\text {nano }} & =50^{\circ} \mathrm{C} \\
\operatorname{Tin}_{\text {Air }} & =25^{\circ} \mathrm{C}
\end{aligned}
$$

$\operatorname{Tin}_{\text {nano }}$ and $\operatorname{Tin}_{A i r}$ are the refrigerant and air inlet temperatures, respectively.

The properties of the nanofluid, which circulates through the flat tubes, are shown below, where $\phi$ is the volume fraction of the nanoparticle. The refrigerant properties are pure water or $50 \%$ ethylene glycol, according to Table 1.

$$
\begin{gathered}
\rho_{\text {nano }}=\phi \rho_{\text {Particle }}+(1-\phi) \rho_{\text {Refr }} \\
\mu_{\text {nano }}=\phi\left[\mu_{\text {Refr }}+(1+2.5 \phi)\right]+(1-\phi) \mu_{\text {Refr }} \\
C p_{\text {nano }}=\frac{\left[\phi \rho_{\text {Particle }} C p_{\text {Particle }}+(1-\phi) \rho_{\text {Refr }} C p_{\text {Refr }}\right]}{\rho_{\text {nano }}}
\end{gathered}
$$




$$
\begin{gathered}
K_{\text {nano }}=\frac{\left[K_{\text {particle }}+2 K_{\text {Refr }}+2\left(K_{\text {Particle }}-K_{\text {Refr }}\right)(1+0.1)^{3} \phi\right] k_{\text {Refr }}}{\left[K_{\text {particle }}+2 K_{\text {Refr }}-\left(K_{\text {Particle }}-K_{\text {Refr }}\right)(1+0.1)^{2} \phi\right]} \\
v_{\text {nano }}=\frac{\mu_{\text {nano }}}{\rho_{\text {nano }}} \\
\alpha_{\text {nano }}=\frac{K_{\text {nano }}}{\rho_{\text {nano }} C p_{\text {nano }}} \\
P r_{\text {nano }}=\frac{v_{\text {nano }}}{\alpha_{\text {nano }}} \\
d t u b=1.3 \times 10^{-3} \mathrm{~m} \\
\text { Dtube }=25.6 \times 10^{-3} \mathrm{~m}
\end{gathered}
$$

$d t u b$ and $D t u b e$ are the smallest and largest diameters of the flat tube.

$$
D h t u b=\frac{\left[\pi d t u b^{2}+(D t u b e-d t u b) d t u b\right]}{[\pi d t u b+2(D t u b e-d t u b)]}
$$

$D h t u b$ is the hydraulic diameter associated with the flat tube.

$$
\begin{gathered}
\text { Astub }=\frac{\pi D h t u b^{2}}{4} \\
L t u b=553.5 \times 10^{-3} \mathrm{~m} \\
\text { Atub }=\pi \text { Dhtub Ltub }
\end{gathered}
$$

$A t u b$ is the heat exchange area of a single tube.

$$
\begin{gathered}
\text { Asup }=\text { Atub Ntub } \\
\text { Ntub }=59
\end{gathered}
$$

Asup is the surface area of all tubes in the heat exchanger, where Ntub is the number of tubes.

The average velocity associated with the nanofluid is given by:

$$
\begin{gathered}
\text { Vmed }=\frac{4 \dot{m}_{\text {nano }}}{\rho_{\text {nano }} D h t u b^{2}} \\
R e_{\text {nano }}=\frac{4 \dot{m}_{\text {nano }}}{N t u b \pi D h t u b \mu_{\text {nano }}}
\end{gathered}
$$

$R e_{\text {nano }}$ is the Reynolds number associated with the nanofluid.

$$
\begin{aligned}
N u_{\text {nano }}= & 4.364+0.0722 \operatorname{Re}_{\text {nano }}\left(\frac{P r_{\text {nano }} D h t u b}{L t u b}\right) \text { for } \operatorname{Re}_{\text {nano }}<2100 \\
N u_{\text {nano }}= & {\left[\left(\operatorname{Re}_{\text {nano }}-2100\right) 0.027 \frac{\left[\left(10^{4}\right)^{0.8}\left(P r_{\text {nano }}\right)^{\frac{1}{3}}\right)}{\left(10^{4}-2100\right)}\right] } \\
& +\left[\frac{\left(10^{4}-R e_{\text {nano }}\right)\left[4.364+0.0722 R e_{\text {nano }}\left(\frac{P r_{\text {nano }} D h t u b}{L t u b}\right)\right]}{\left(10^{4}-2100\right)}\right]
\end{aligned}
$$


$N u_{\text {nano }}$ is the Nusselt number associated with the nanofluid.

$$
h_{\text {nano }}=\frac{N u_{\text {nano }} K_{\text {nano }}}{D h t u b}
$$

$h_{\text {nano }}$ is the convective heat transfer coefficient of the nanofluid.

$$
\begin{gathered}
\dot{m}_{A i r}=R e_{A i r} * \frac{\tau_{A i r} * A_{F r} * \mu_{A i r}}{D h_{A i r}} \\
\tau_{\text {Air }}=\frac{\text { Fin Area }}{\text { Total Area }}=0.795 ; A_{F r}=9.45 \times 10^{-3} \mathrm{~m}^{2} ; D h_{A i r}=3.51 \times 10^{-3} \mathrm{~m} . \\
G_{A i r}=\frac{\dot{m}_{A i r}}{\tau_{A i r} * A_{F r}} \\
h_{A i r}=J G_{A i r} \operatorname{Cp}_{\text {Air }} \operatorname{Pr}_{\text {Air }}^{\left(-\frac{2}{3}\right)}
\end{gathered}
$$

$R e_{A i r}$ is the Reynolds number associated with the air. $h_{A i r}$ is the convective heat transfer coefficient of the air.

$J$ is the Colbourn factor and is given by (Kays and London [9], Pag. 271, Fig. 10-93):

$$
\begin{gathered}
J=0.11101-0.000836695 e_{A i r}+2.889452778 \times 10^{-6} R e_{A i r}^{2} \\
-5.2675 \times 10^{-9} R e_{A i r}^{3}+5.298611111 \times 10^{-11} R e_{A i r}^{4} \\
\quad-2.8 \times 10^{-15} R e_{A i r}^{5}+6.111111111 \times 10^{-19} R e_{A i r}^{6} \text { for } R e_{A i r} \leq 10^{3} \\
J=0.01066-6.457142857 \times 10^{-6} R e_{A i r}+2.014285714 \times 10^{-9} R e_{A i r}^{2} \\
-2 \times 10^{-13} R e_{A i r}^{3} \text { for } 10^{3}<R e_{A i r} \leq 3 \times 10^{3} \\
J=0.004279006426+5.740813973 \times 10^{-8} R e_{A i r}-5.917655297 \times 10^{-11} R e_{A i r}^{2} \\
+4.0455594 \times 10^{-15} R e_{A i r}^{3} \text { for } 3 \times 10^{3}<R e_{A i r} \\
N u_{A i r}=h_{A i r} \frac{D h_{\text {air }}}{K_{A i r}}
\end{gathered}
$$

$N u_{A i r}$ is the Nusselt number associated with the air.

$$
U o=\frac{1}{\frac{1}{h_{\text {Air }}}+\frac{1}{h_{\text {nano }}}}
$$

Uo is the overall heat transfer coefficient.

$$
\begin{aligned}
C_{\text {Air }} & =\dot{m}_{\text {Air }} C p_{\text {Air }} \\
C_{\text {nano }} & =\dot{m}_{\text {nano }} C p_{\text {nano }}
\end{aligned}
$$

$C_{A i r}$ and $C_{\text {nano }}$ are the heat capacity of air and nanofluid, respectively.

$$
N T U=\frac{A \sup U o}{C \min }
$$

$N T U$ is the number of thermal units, or nondimensional heat transfer size, associated with the heat exchanger under analysis, and Cmin is the minimum between $C_{A i r}$ and $C_{\text {nano }}$. 


$$
\begin{gathered}
C^{*}=\frac{C \min }{C \max } \\
F a=\frac{N T U\left(1-C^{*}\right)}{2} \\
\eta=\frac{\operatorname{Tanh}(F a)}{F a} \\
\varepsilon=\frac{1}{\frac{1}{\eta N T U}+\frac{1+C^{*}}{2}}
\end{gathered}
$$

$\eta$ and $\varepsilon$ are the efficiency and effectiveness associates with the heat exchanger, respectively. $\mathrm{Fa}$ is the fin analogy number.

$$
\begin{array}{r}
\dot{Q}_{\text {max }}=\operatorname{Cmin} *\left(\operatorname{Tin}_{\text {Refr }}-\operatorname{Tin}_{\text {Air }}\right) \\
\dot{Q}=\left(\operatorname{Tin}_{\text {nano }}-\operatorname{Tin}_{\text {Air }}\right) \frac{\operatorname{Cmin}}{\frac{1}{(\eta N T U)+\frac{1+C^{*}}{2}}}
\end{array}
$$

$\dot{Q}$ is the heat transfer rate for the Efficiency and Effectiveness Method.

$$
\begin{gathered}
\text { Tout }_{\text {nano }}=\operatorname{Tin}_{\text {nano }}-\frac{\dot{Q}}{C_{\text {nano }}} \\
\text { Tout }_{\text {Air }}=\frac{\dot{Q}}{C_{\text {nano }}}+\operatorname{Tin}_{\text {Air }}
\end{gathered}
$$

\section{2. $\varepsilon-N T U$ Method}

$$
\begin{gathered}
k_{\text {Fin }}=235 \frac{\mathrm{W}}{\mathrm{m} \cdot \mathrm{K}} \\
L_{\text {Fin }}=0.05 \times 10^{-3} \mathrm{~m} \\
A s_{\text {air }}=3.98 \mathrm{~m}^{2} \\
A s_{\text {nano }}=\text { Asup } \\
m_{L}=\frac{2 h_{\text {Air }}}{k_{\text {Fin }} L_{\text {Fin }}} \\
\eta_{\text {Fin }}=\frac{\text { Tanh }\left(m_{L}\right)}{m_{L}}
\end{gathered}
$$

$\eta_{\text {Fin }}$ is the efficiency of the fin.

$$
\begin{gathered}
\beta=\frac{\text { Area }_{\text {Fin }}}{\text { Area }_{\text {Tot }}} \\
\eta^{\prime}=\beta \eta_{\text {Fin }}+1-\beta
\end{gathered}
$$

$\eta^{\prime}$ is the efficiency associated with the heat exchanger for the $\varepsilon$-NTU Method. 


$$
\begin{gathered}
A_{\text {Med }}=\frac{A s_{\text {Air }}+A s_{\text {nano }}}{2} \\
\text { AaUa }=\frac{1}{\frac{1}{\eta^{\prime} h_{\text {Air }}}+\frac{L_{\text {Fin }}}{\left(\frac{A s_{\text {Med }}}{A s_{\text {Air }}}\right) k_{\text {Fin }}}+\frac{1}{\left(\frac{A s_{\text {nano }}}{A s_{\text {Air }}}\right) h_{\text {nano }}}} \\
N T U_{\epsilon}=\frac{A a U a}{C m i n}
\end{gathered}
$$

$N T U_{\epsilon}$ is the number of thermal units, or nondimensional heat transfer size, for the $\varepsilon$-NTU Method.

$$
\varepsilon_{N T U}=1-\left[\operatorname{Exp}\left[C^{*(-1)} N T U_{\epsilon}^{(-1.22)}\left(\operatorname{Exp}\left(-C^{*} N T U_{\epsilon}^{0.78}-1\right)\right)\right]\right]
$$

$\varepsilon_{N T U}$ is the empirical Effectiveness for the $\varepsilon$-NTUMethod Kakaç, Sadik [10].

$$
\begin{gathered}
\dot{Q}_{N T U}=\varepsilon_{N T U} \operatorname{Cmin}\left(\operatorname{Tin}_{\text {Refr }}-\operatorname{Tin}_{A i r}\right) \\
\text { Tnano }_{N T U}=\operatorname{Tin}_{\text {nano }}-\frac{\dot{Q}_{N T U}}{C_{\text {nano }}} \\
\text { Tair }_{N T U}=\frac{\dot{Q}_{N T U}}{C_{\text {nano }}}+\operatorname{Tin}_{\text {Air }} \\
E_{\dot{Q}}=\left|\frac{\dot{Q}-\dot{Q}_{N T U}}{\dot{Q}_{N T U}}\right| \\
E_{\varepsilon}=\left|\frac{\varepsilon-\varepsilon_{N T U}}{\varepsilon}\right|
\end{gathered}
$$

$E_{\dot{Q}}$ is the absolute error for comparing the heat transfer rates of the models considered here and $E_{\varepsilon}$ is the absolute error for Effectiveness.

\section{Results and Discussion}

Figures 2-4 show results for density, thermal conductivity, and specific heat, with variation in volume fraction for nanoparticles, for pure water, and 50\% ethylene glycol. Density and thermal conductivity are slightly higher for ethylene glycol and slightly lower for thermal capacity. The result obtained for the thermal capacity stands out since a lower value means less energy retention in the form of heat for steady state. Less heat retention means more heat exchange with the medium.

Figure 5 presents results for the Nusselt number for the nanofluid, with superior results for the $50 \%$ ethylene glycol compound. It is to be expected, in this case, that the ethylene glycol compound will present better thermal performance than water for a given nanofluid flow rate.

Figure 6 presents the Nusselt number for air as a function of the Reynolds number. Again, the Nusselt number grows with the Reynolds number, and, in this case, it is to be expected that a greater airflow will produce greater thermal performance. 


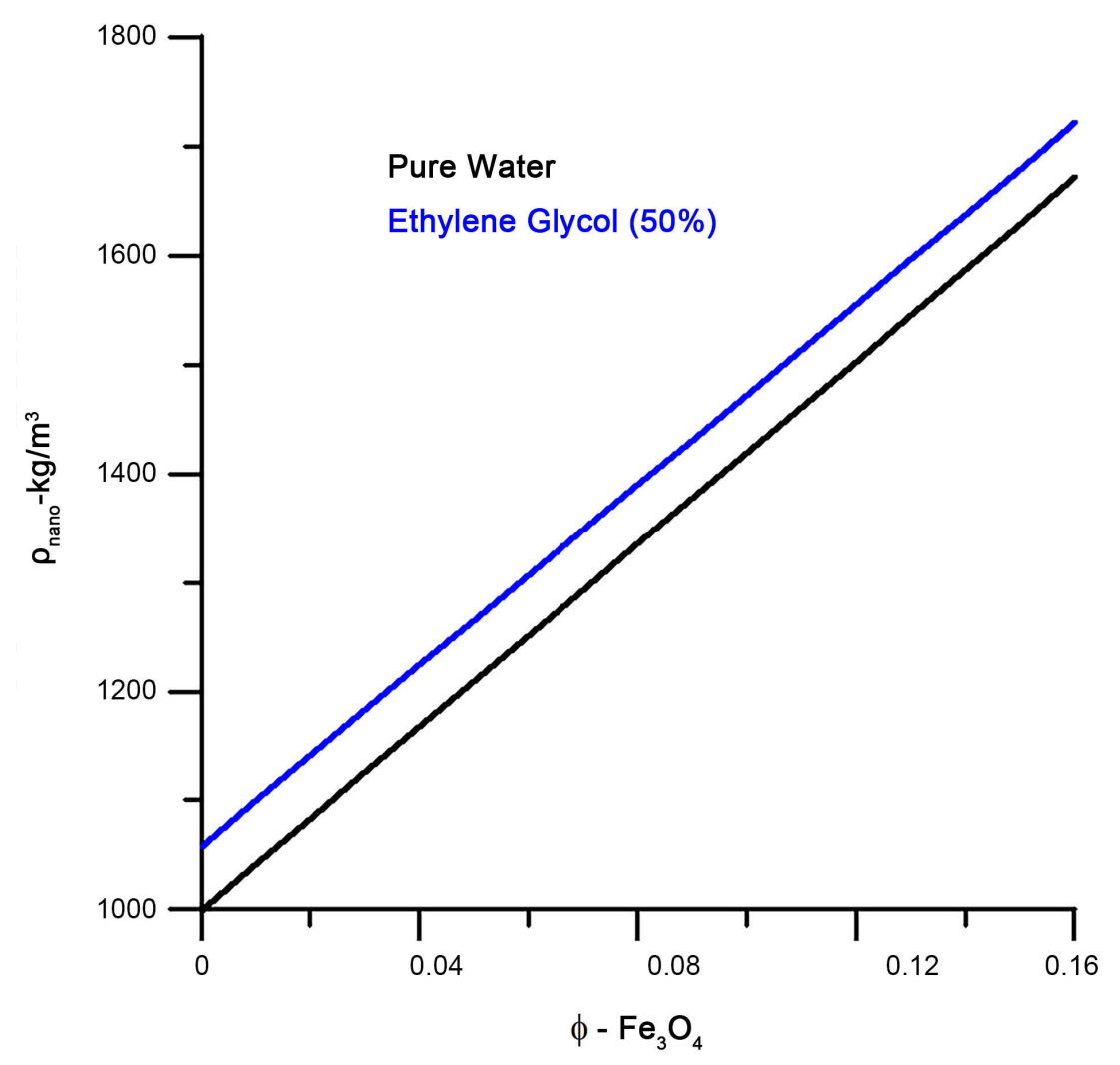

Figure 2. Density versus volume fraction of iron oxide $\left(\mathrm{Fe}_{3} \mathrm{O}_{4}\right)$.

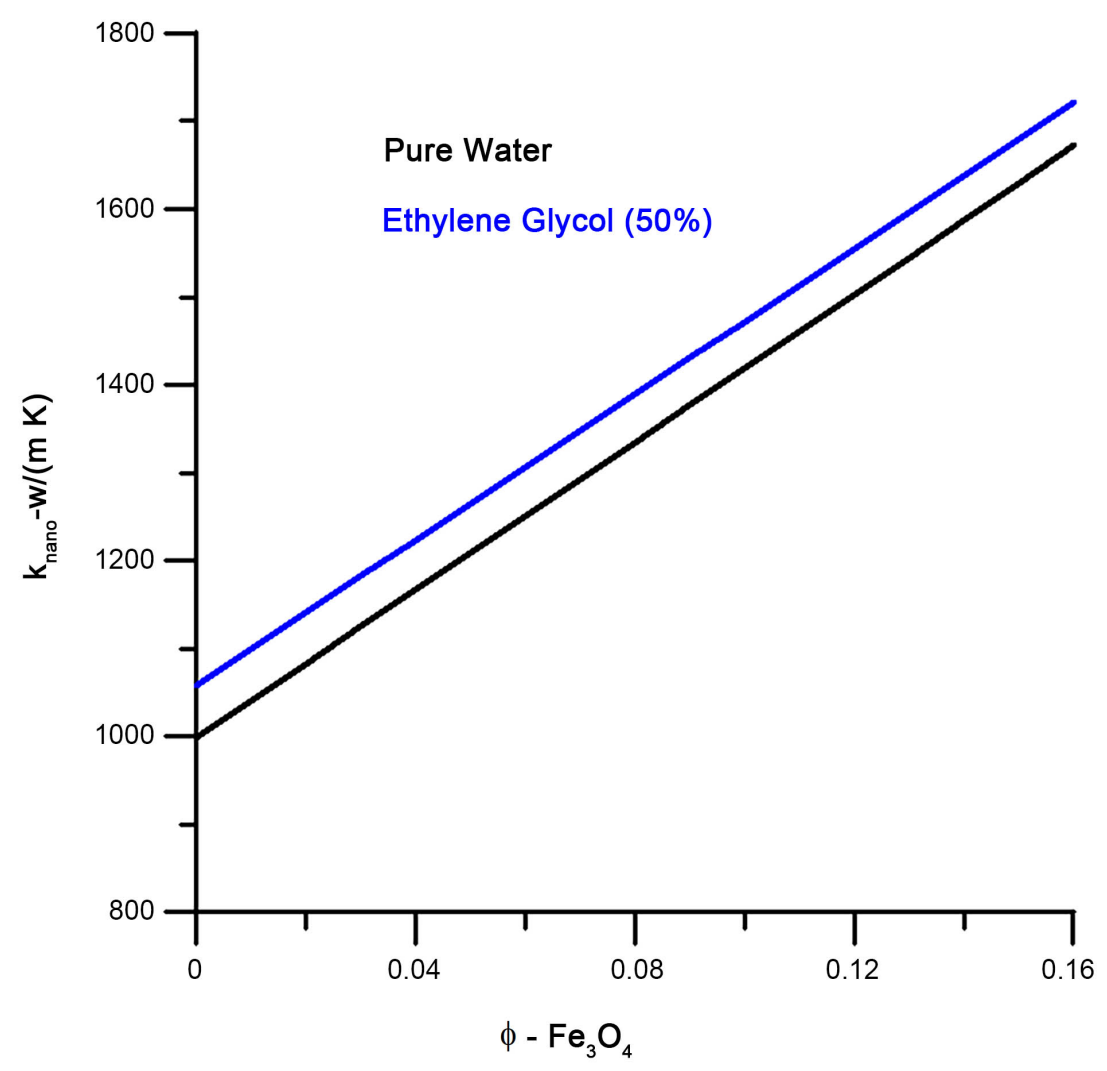

Figure 3. Thermal conductivity versus volume fraction of iron oxide $\left(\mathrm{Fe}_{3} \mathrm{O}_{4}\right)$. 


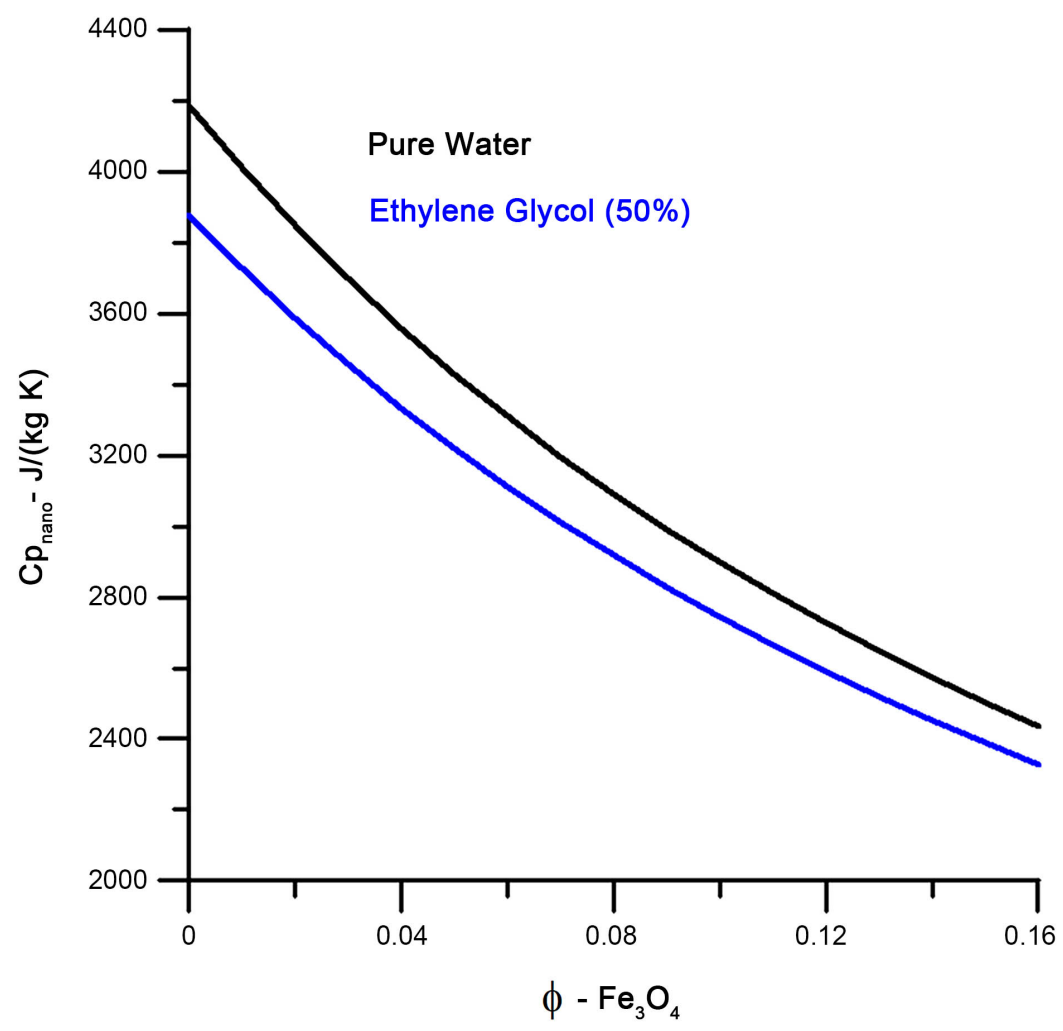

Figure 4. Specific heat versus volume fraction of iron oxide $\left(\mathrm{Fe}_{3} \mathrm{O}_{4}\right)$.

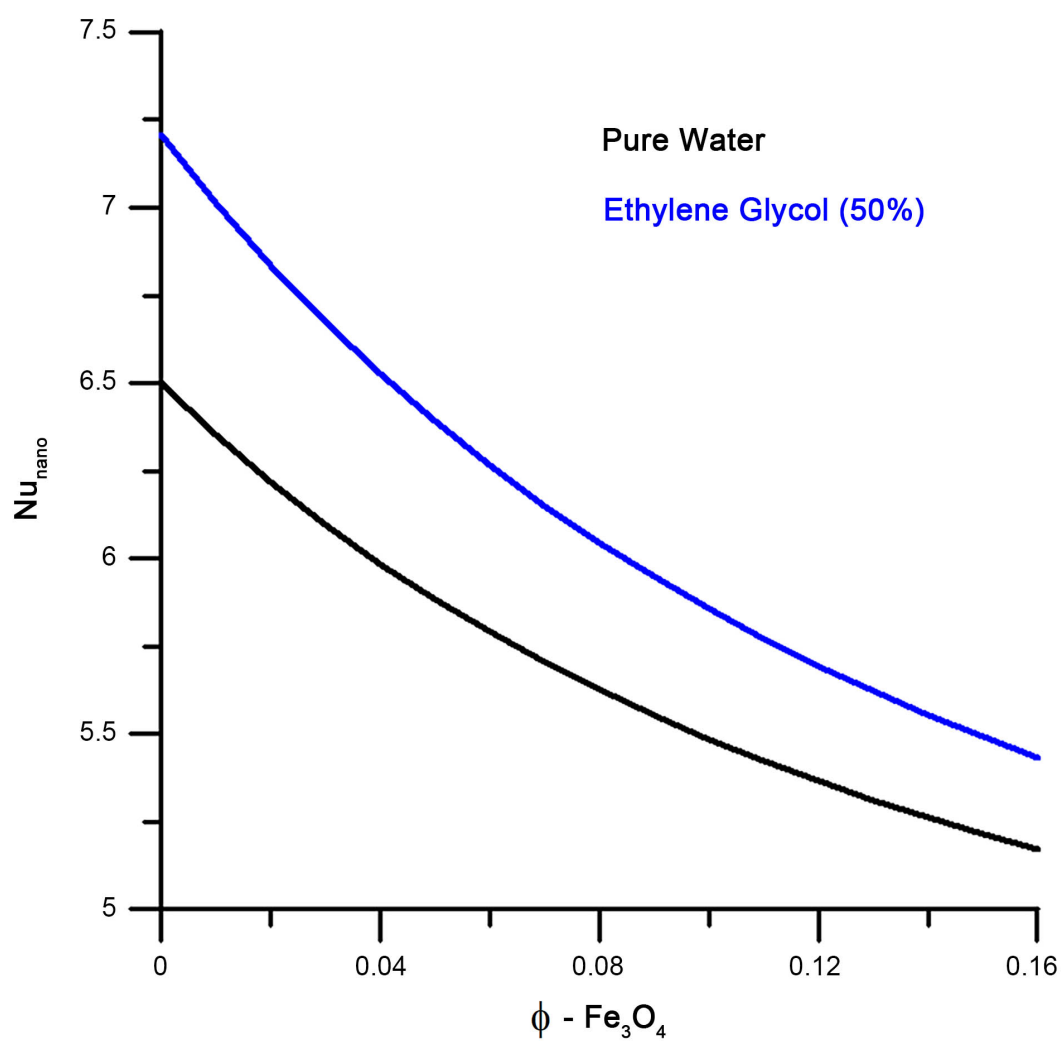

Figure 5. Nusselt number for the nanofluid versus volume fraction of iron oxide $\left(\mathrm{Fe}_{3} \mathrm{O}_{4}\right) \quad \dot{m}_{\text {nano }}=0.11 \mathrm{~kg} / \mathrm{s}$. 


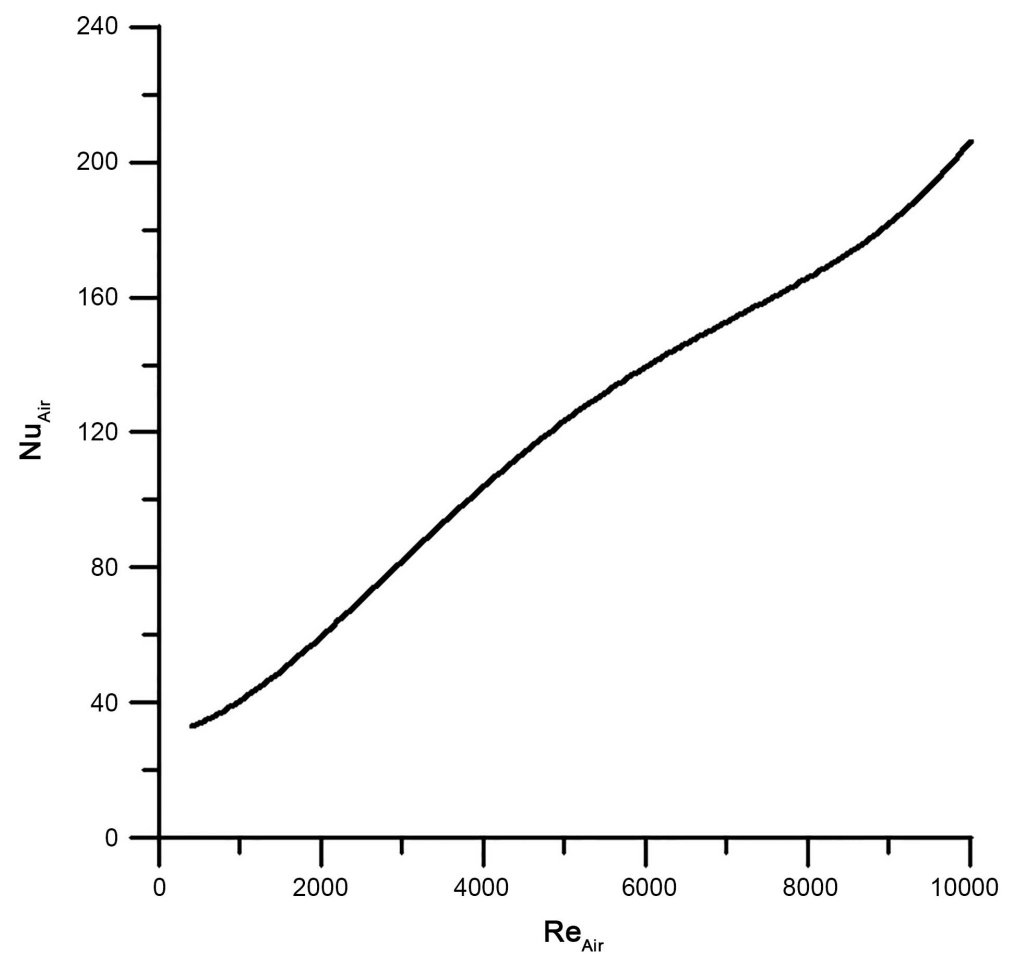

Figure 6. Nusselt number for the air versus Reynolds number of the air.

Figure 7 shows nanofluid exit temperature results for the two methods compared in this work, with the Reynolds number for air varying over a wide range of values. For a relatively low Reynolds number, the models are practically equal concerning the exit temperature for the nanofluid in all nanoparticle volume fractions considered. For Reynolds number values for air above 4000, the Efficiency and Effectiveness model presents significantly lower output results than the $\varepsilon$-NTU model. It is noteworthy that, for Reynolds number for air close to and above 6000, the volume fraction necessary to achieve maximum efficiency for the system in question significantly decreases. The promising result is that the cost of nanofluid can be reduced by increasing power in the ventilation system. It is evident that, in this case, a cost-benefit analysis is necessary, which goes beyond the scope of this work.

Figure 8 shows that the ethylene glycol 50\% compound has slightly better thermal performance than pure water. It is important to emphasize, in this case, that the use of ethylene glycol reduces the reactive effect of water on the environment, increasing the average life of the equipment.

Figure 9 shows air exit temperature results for the two methods compared in this work, with the Reynolds number for air varying over a wide range of values. However, for a relatively low Reynolds number, the models are practically equal concerning the exit temperature for the air in all nanoparticle volume fractions considered.

Figure 10 shows that the ethylene glycol $50 \%$ compound has slightly better thermal performance than pure water. 


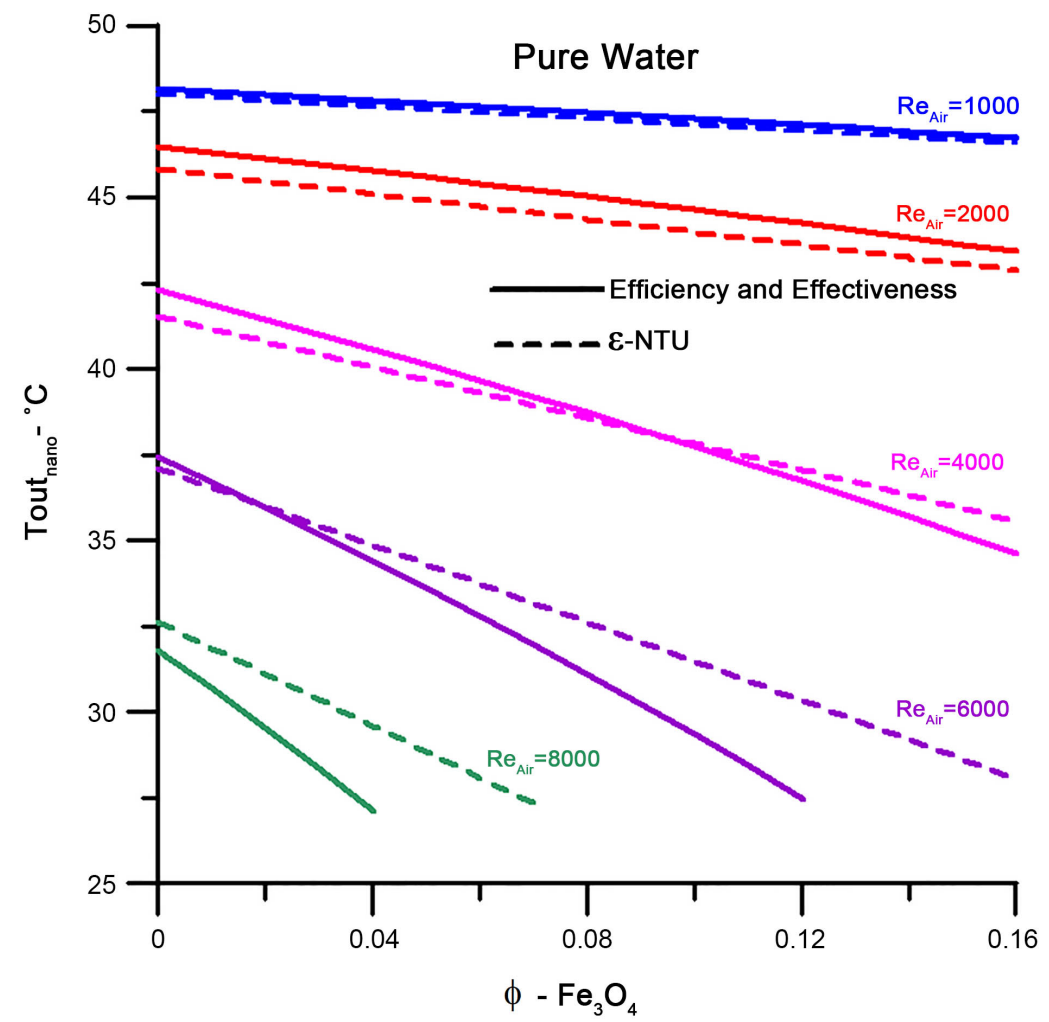

Figure 7. Temperature exits for the nanofluid versus volume fraction of iron oxide $\left(\mathrm{Fe}_{3} \mathrm{O}_{4}\right)$ to the comparison of the two models $\left(\dot{m}_{\text {nano }}=0.11 \mathrm{~kg} / \mathrm{s}\right)$.

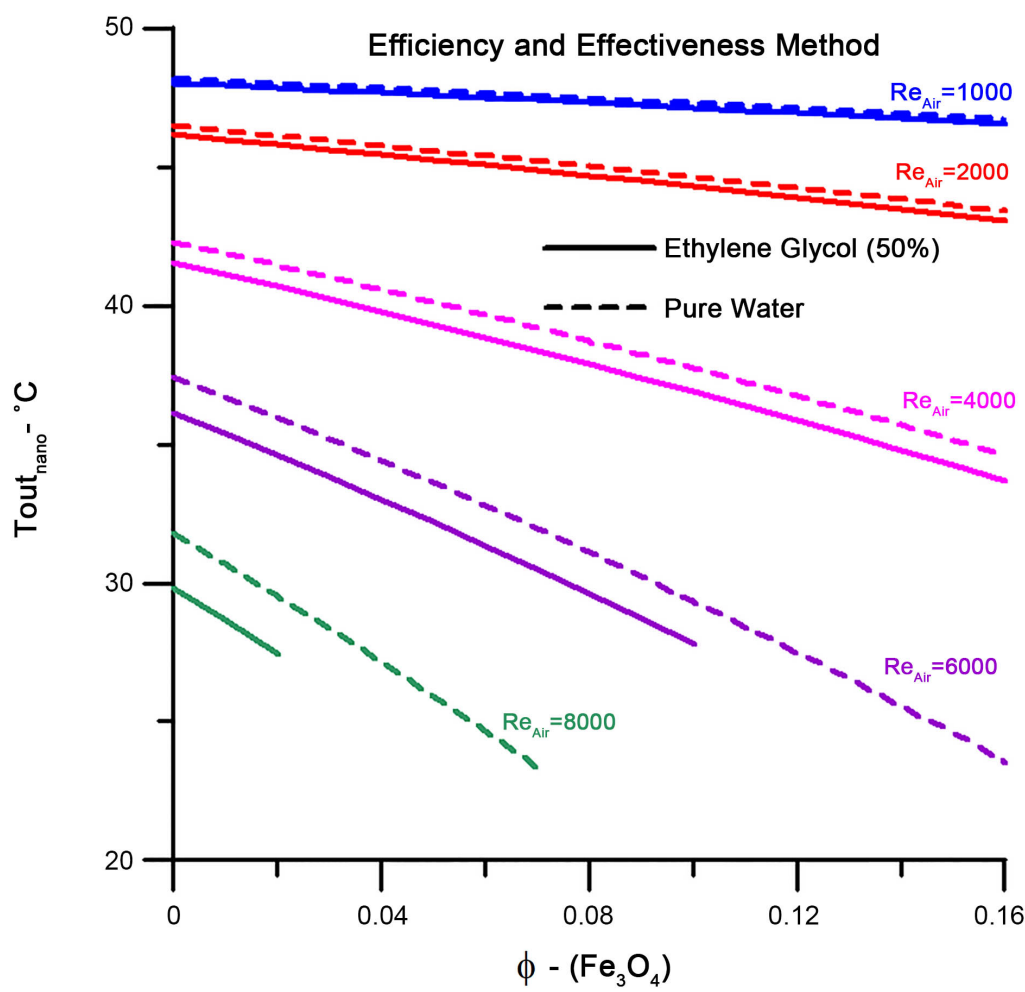

Figure 8. Temperature exits for the nanofluid versus volume fraction of iron oxide $\left(\mathrm{Fe}_{3} \mathrm{O}_{4}\right)$ for pure water and ethylene glycol $50 \%\left(\dot{m}_{\text {nano }}=0.11 \mathrm{~kg} / \mathrm{s}\right)$. 


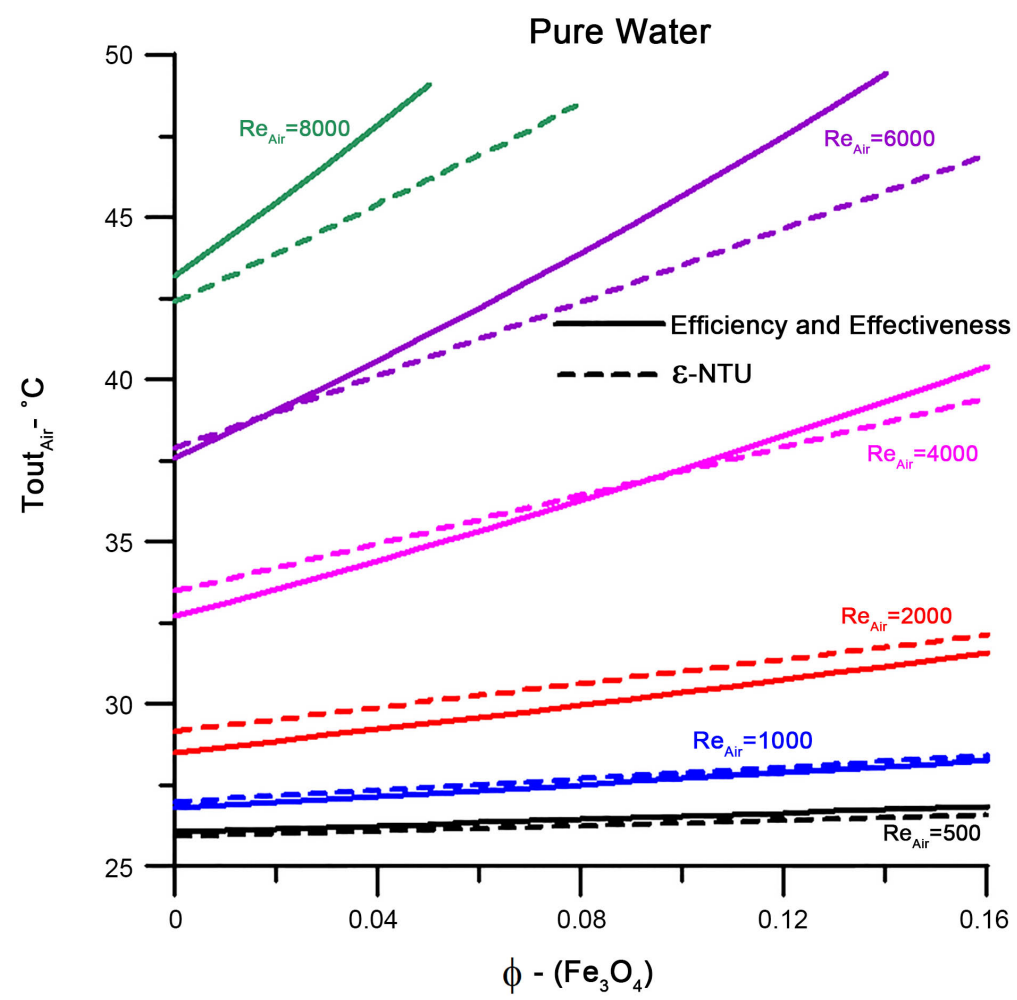

Figure 9. Temperature exits for the air versus volume fraction of iron oxide $\left(\mathrm{Fe}_{3} \mathrm{O}_{4}\right)$ to the comparison of the two models $\left(\dot{m}_{\text {nano }}=0.11 \mathrm{~kg} / \mathrm{s}\right)$.

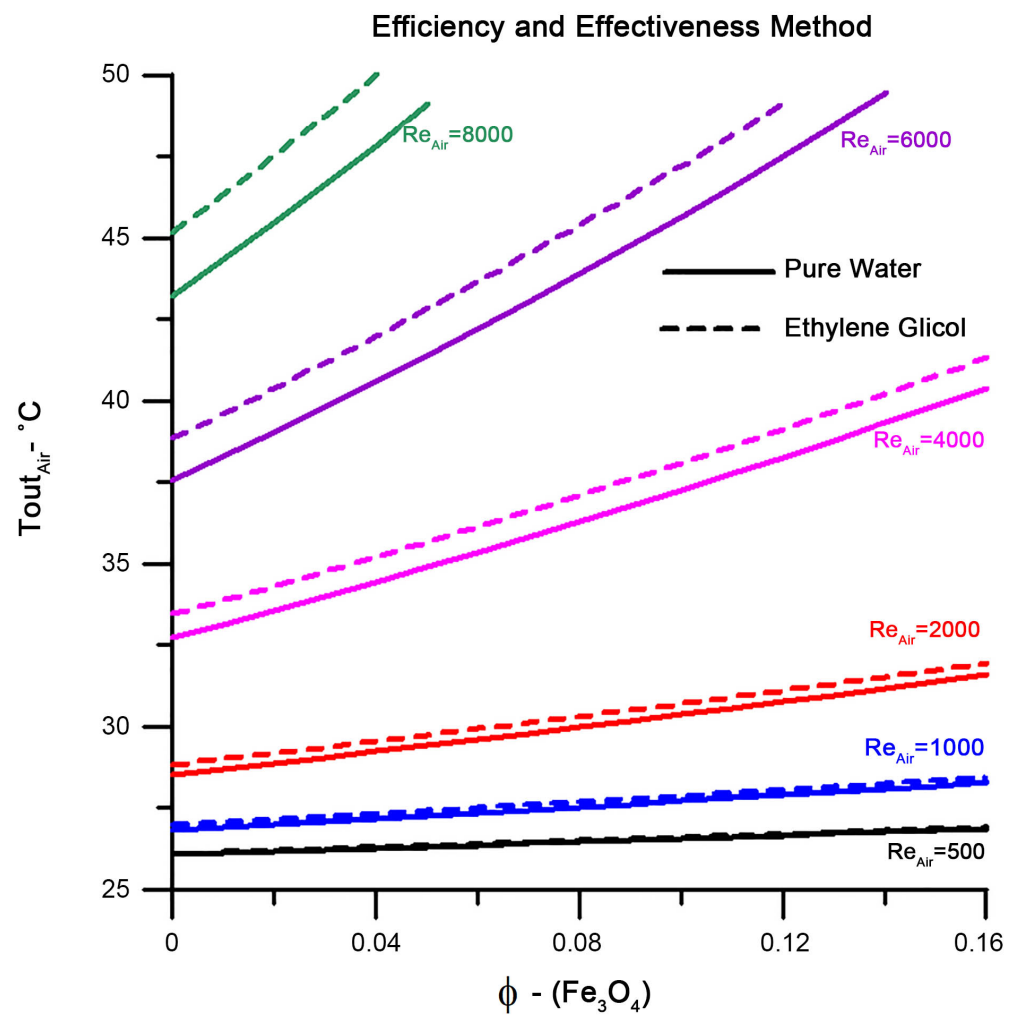

Figure 10. Temperature exits for the air versus volume fraction of iron oxide $\left(\mathrm{Fe}_{3} \mathrm{O}_{4}\right)$ for pure water and ethylene glycol $50 \%\left(\dot{m}_{\text {nano }}=0.11 \mathrm{~kg} / \mathrm{s}\right)$. 
Figure 11 shows results for nanofluid exit temperature for two mass flow values, $\dot{m}_{\text {nano }}=0.11 \mathrm{~kg} / \mathrm{s}$ e $\dot{m}_{\text {nano }}=0.31 \mathrm{~kg} / \mathrm{s}$, with Reynolds number of air ranging from 400 to 8000 . The nanoparticle fractions range from 0.01 to 0.15 . For the flow with lower thermal capacity $\left(\dot{m}_{\text {nano }}=0.11 \mathrm{~kg} / \mathrm{s}\right.$ ), and the more significant the volume fraction of the nanoparticles, the better the thermal performance, that is, the lower the nanofluid exit temperature. Furthermore, the airflow to achieve maximum performance decreases with higher nanoparticle fractions.

Figure 12 shows results for air outlet temperature for two mass flow values, $\dot{m}_{\text {nano }}=0.11 \mathrm{~kg} / \mathrm{s}$ e $\dot{m}_{\text {nano }}=0.31 \mathrm{~kg} / \mathrm{s}$, with Reynolds number of air ranging from 400 to 8000 . The nanoparticle fractions range from 0.01 to 0.15 . For the flow with lower thermal capacity $\left(\dot{m}_{\text {nano }}=0.11 \mathrm{~kg} / \mathrm{s}\right.$ ), and the more significant the volume fraction of the nanoparticles, the better the thermal performance, that is, the higher the air outlet temperature. Furthermore, the airflow to achieve maximum performance decreases with higher nanoparticle fractions.

The absolute relative error between the models, for the two types of fluids (Pure Water and Ethylene Glycol 50\%), reaches a maximum value of $16 \%$ when the reference is the Efficiency and Effectiveness Method and 20\% when the reference is the Method $\varepsilon$-NTU, according to Figure 13 and Figure 14. The maximum value is reached for the highest number of Reynolds of air. Considering that the Effectiveness of the $\varepsilon$-NTU Method is obtained empirically for the type of heat exchanger in question, Kays and London (1987) and that Colburn's dimensionless factor is obtained experimentally, a maximum of $20 \%$ error is justifiable.

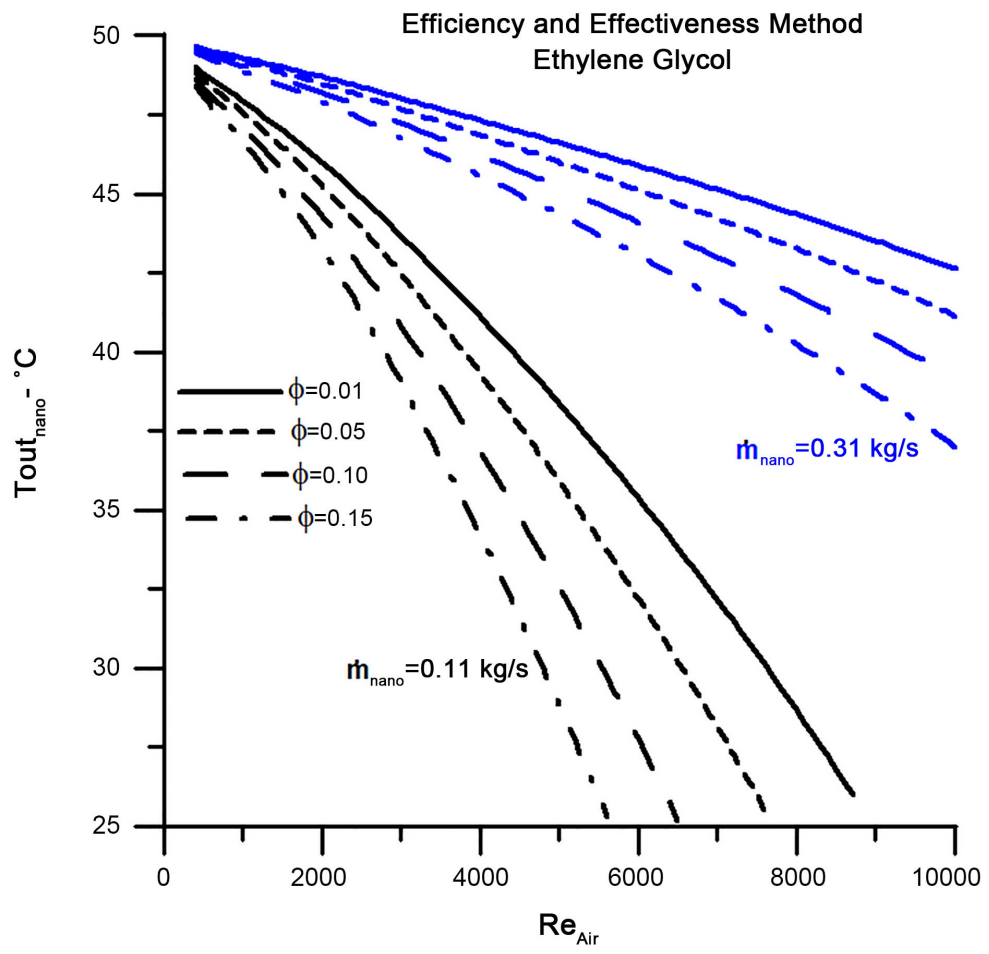

Figure 11. Temperature exits for the nanofluid versus volume fraction of iron oxide $\left(\mathrm{Fe}_{3} \mathrm{O}_{4}\right)$, with nanofluid flow rate variation, to the comparison of the two models. 


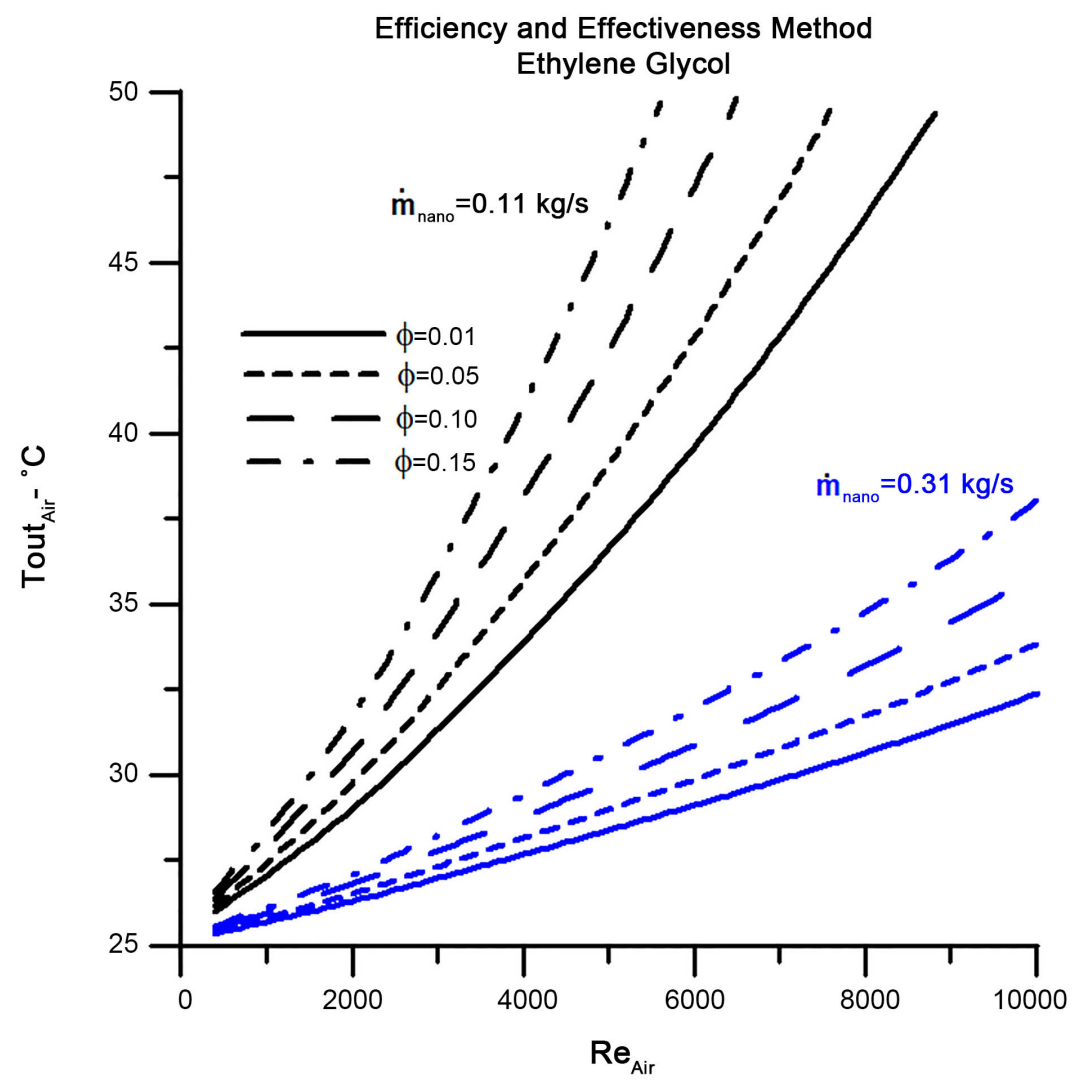

Figure 12. Temperature exits for the air versus volume fraction of iron oxide $\left(\mathrm{Fe}_{3} \mathrm{O}_{4}\right)$, with nanofluid flow rate variation, to the comparison of the two models.

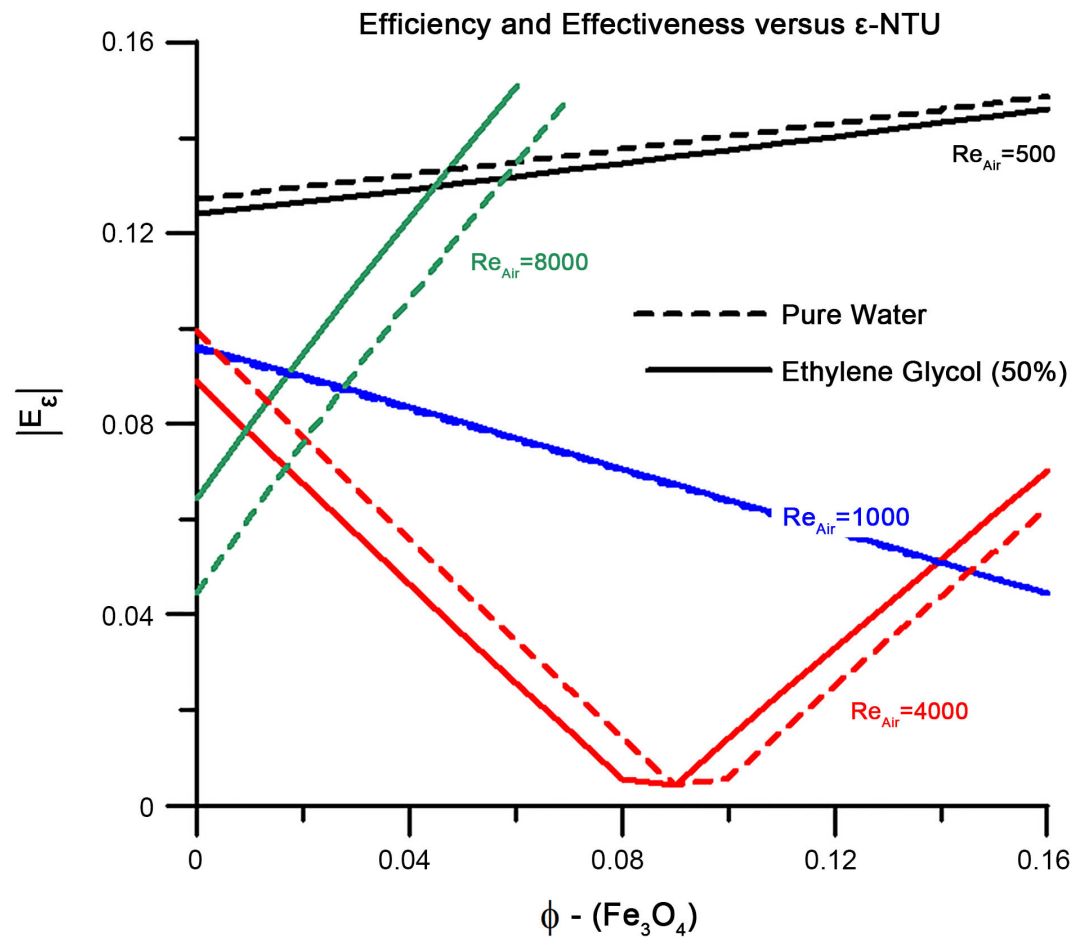

Figure 13. Absolute relative error between models for Effectiveness, with the $\varepsilon$-NTU Method as reference. 


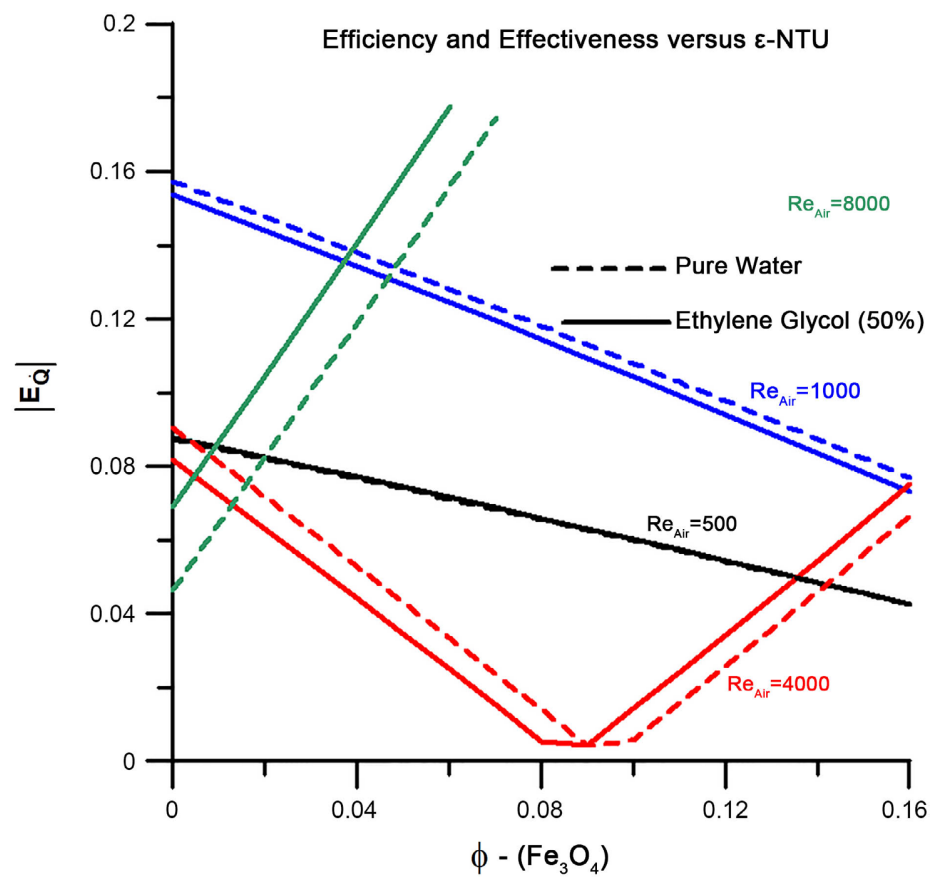

Figure 14. Absolute relative error between models for heat transfer rate, with Efficiency and Effectiveness Method as reference.

\section{Conclusions}

Ethylene glycol 50\% compound has slightly better thermal performance than pure water.

For a relatively low Reynolds number of the air, the models are practically equal concerning the exit temperature for the nanofluid in all nanoparticle volume fractions considered. However, for Reynolds number values for air above 4000, the Efficiency and Effectiveness model presents significantly lower temperature nanofluid output results than the $\mathcal{\varepsilon}$-NTU model.

For Reynolds number for the air close to and above 6000, the volume fraction necessary to achieve maximum efficiency for the system in question significantly decreases. The promising result is that the cost of nanofluid can be reduced by increasing power in the ventilation system.

The airflow to achieve maximum performance decreases with higher nanoparticle fractions.

The absolute relative error between the models reaches a maximum value of $16 \%$ when the reference is the Efficiency and Effectiveness Method and 20\% when the reference is the Method $\varepsilon$-NTU.

Finally, it is suggested the evaluation of new non-metallic nanoparticles to be used in the radiator, for example, carbon nanotubes, which allow higher values for thermal conductivity.

\section{Conflicts of Interest}

The author declares no conflicts of interest regarding the publication of this paper. 


\section{References}

[1] Leong, K.Y., Saidur, R., Khairulmaini, M., Michael, Z. and Kamyar, A. (2012) Heat Transfer and Entropy Analysis of Three Different Types of Heat Exchangers Operated with Nanofluids. International Communications in Heat and Mass Transfer, 39, 838-843. https://doi.org/10.1016/j.icheatmasstransfer.2012.04.003

[2] Tiwari, R. and Maheshwari, G. (2017) Effectiveness and Efficiency Analysis of Parallel Flow and Counter Flow Heat Exchangers. International Journal of Application or Innovation in Engineering \& Management, 6, 314-319.

[3] Fakheri, A. (2007) Heat Exchanger Efficiency. Journal of Heat Transfer, 129, 1268-1276. https://doi.org/10.1115/1.2739620

[4] Selvam, C., Mohan, L.D. and Sivasankaran, H. (2017) Enhanced Heat Transfer Performance of an Automobile Radiator with Graphene-Based Suspensions. Applied Thermal Engineering, 123, 50-60.

https://doi.org/10.1016/j.applthermaleng.2017.05.076

[5] Nogueira, E. (2020) Thermal Performance in Heat Exchangers by the Irreversibility, Effectiveness, and Efficiency Concepts Using Nanofluids. Journal of Engineering Sciences, 7, F1-F7. https://doi.org/10.21272/jes.2020.7(2).f1

[6] Hussein, A.M., Kadirgama, K., Sharma, K.V., Ramasamy, D. and Bakar, R. (2017) Heat Transfer Enhancement with Nanofluids for Automotive Cooling. In: Korada V., Hisham, B. and Hamid, N., Eds., Engineering Applications of Nanotechnology. Topics in Mining, Metallurgy, and Materials Engineering, Springer, Cham. https://doi.org/10.1007/978-3-319-29761-3_3

[7] Nogueira, E. (2020) The Effectiveness Method ( $\varepsilon$-NTU) to Analyze the Thermal Performance of the Flat Tube Multi-Louvered Finned Radiator with Silver Nanoparticles Suspension in Ethylene Glycol. International Journal of Advanced Technology and Engineering Exploration, 7, 102-112. https://doi.org/10.19101/IJATEE.2020.762040

[8] Nogueira, E. (2020). Thermal-Hydraulic Performance of Graphene Nanoribbon and Silicon Carbide Nanoparticles in the Multi-Louvered Radiator for Cooling Diesel Engine. Journal of Engineering Sciences, 7, F22-F29. https://doi.org/10.21272/jes.2020.7(1).f2

[9] Kays, W.M. and London, A.L. (1984) Compact Heat Exchangers. MacGraw-Hill, New York.

[10] Kakaç, S. (1991) Boilers, Evaporators, and Condensers. John Wiley \& Sons, Hoboken. 